\title{
Hydrogen peroxide concentration and DNA fragmentation of buffalo oocytes matured in sericin-supplemented maturation medium
}

\author{
S. Gustina ${ }^{1}$, N.W.K. Karja ${ }^{3 \#}$, H. Hasbi ${ }^{2}$, M.A. Setiadi ${ }^{3}$ \& I. Supriatna ${ }^{3}$ \\ ${ }^{1}$ Division of Animal Science, Faculty of Animal Science and Fisheries, Sulawesi Barat University, Majene 91412 , \\ Sulawesi Barat, Indonesia \\ ${ }^{2}$ Department of Animal Production, Faculty of Animal Science, Hasanuddin University, Makassar 90245, Sulawesi \\ Selatan, Indonesia \\ ${ }^{3}$ Division of Reproduction and Obstetrics, Department of Veterinary Clinic, Reproduction, and Pathology, Bogor \\ Agricultural University, Bogor 16680, Jawa Barat, Indonesia
}

(Received 10 September 2018; Accepted 8 January 2019; First published online 3 April 2019)

\author{
Copyright resides with the authors in terms of the Creative Commons Attribution 4.0 South African Licence. \\ See: http://creativecommons.org/licenses/by/4.0/za \\ Condition of use: The user may copy, distribute, transmit and adapt the work, but must recognise the authors and \\ the South African Journal of Animal Science.
}

\begin{abstract}
This study was conducted to investigate the effects of sericin on meiotic maturation, hydrogen peroxide $\left(\mathrm{H}_{2} \mathrm{O}_{2}\right)$ concentration and deoxyribonucleic acid (DNA) fragmentation in buffalo oocytes. Oocytes were matured in vitro in tissue culture medium (TCM-199) with in vitro maturation (IVM) groups under several conditions, namely without bovine serum albumin (-BSA), (+BSA), and $0.025 \%, 0.05 \%, 0.1 \%$ and $0.25 \%$ $(\mathrm{w} / \mathrm{v})$ sericin. The results showed that supplementation of the maturation medium with $0.05 \%$ sericin significantly increased the rate of oocytes that reach metaphase II compared with other groups, except for the $0.025 \%$ sericin-treated group. Intracellular $\mathrm{H}_{2} \mathrm{O}_{2}$ concentrations in oocytes of all groups were measured using 2',7'-dichlorodihydrofluorescein diacetate (DCHFDA). The concentration of $\mathrm{H}_{2} \mathrm{O}_{2}$ in matured oocytes treated with $0.05 \%$ sericin was lower than in other groups. DNA fragmentation and the nuclear status of oocytes were examined using the terminal deoxyribonucleotidyl transferase-mediated dUTP digoxigenin nick end-labelling (TUNEL) method. The total proportion of TUNEL-positive oocytes at the MII stage was lower in the $0.05 \%$ sericin group. The results indicate that addition of $0.05 \%$ sericin to the maturation medium may improve nuclear maturation and may inhibit DNA fragmentation in oocytes by decreasing $\mathrm{H}_{2} \mathrm{O}_{2}$ concentrations.
\end{abstract}

Keywords: antioxidant, apoptosis, in vitro maturation, reactive oxygen species

\# Corresponding author: karjanwk13@gmail.com

\section{Introduction}

In buffalo, the efficiency of in vitro embryo production (IVEP) is still low (Neglia et al., 2003; Drost, 2007). Approximately only $20 \%$ of buffalo oocytes that are fertilized in vitro form blastocysts (Gasparrini, 2002; Nandi et al., 2002; Manjunatha et al., 2008). This inefficiency in buffalo IVEP could be associated with the quality of the oocytes at the beginning of the maturation process, although oocytes were selected based on the compaction of cumulus cells and the homogeneity of ooplasm (Chauhan et al., 1998).

One of the critical factors that could affect the quality of oocytes matured in vitro is the oxygen tension under which oocytes are cultured. In vitro culture environments differ from in vivo conditions. The oxygen tension in in vitro culture systems $(\approx 20 \%)$ is often higher than in the female reproductive tract (3\% to $9 \%)$ (Rocha-Frigoni et al., 2016). This condition is believed to possibly induce the generation of reactive oxygen species (ROS), such as superoxide anions, hydroxyl radicals and hydrogen peroxide $\left(\mathrm{H}_{2} \mathrm{O}_{2}\right)$ (Morado et al., 2009). Reactive oxygen species can modify cell function and endanger the survival of cells that cause fragmentation of DNA, protein oxidation and lipid peroxidation (Yang et al., 1998). High oxygen tension during in vitro maturation and culture might contribute to decreased oocyte quality (Hashimoto et al., 2000) and alter the development of mammalian embryos (Karja et al., 2004). Several enzymatic and non-enzymatic 
antioxidant mechanisms have been developed that protect oocytes and embryos against the harmful effects of ROS (Johnson \& Nasr-Esfahani, 1994). Antioxidants have the roles that they can i) prevent the formation of ROS, ii) inactivate oxidants and iii) possibly limit the deleterious effects of oxidants or repair oxidative damage (Agarwal et al., 2004).

Sericin is a family of proteins that covers fibroin, and as the glue in silkworm cocoons (Takahashi et al., 2003). Sericin is known to have a skin moisturizing and antiwrinkle action owing to its high serine content (Engel et al., 1987). Currently, sericin is used for various purposes, including functional biomaterials (Altman et al., 2003; Cao \& Zhang, 2016), pharmacological purposes (Prommuak et al., 2008), medical uses (Prasong, 2011; Kunz et al., 2016), and food supplements (Zhang, 2002). Sericin is a high molecular weight protein with adhesive properties (Aramwit et al., 2010) and is derived from silkworm cocoons (Dash et al., 2008). Sericin has ROS-scavenging, anti-tyrosinase, anti-elastase (Chlapanidas et al., 2013) and antibacterial properties (Sarovart et al., 2003). It can prevent cell death and supports the growth of cells (Agarwal et al., 2004), increasing the growth of fibroblast cells (Aramwit et al., 2009), and stimulates mammalian cell proliferation (Terada et al., 2002). Sato et al. (2011) explained that sericin promotes growth in a variety of cells and affects mitosis in mammalian cells through various signalling pathways. Furthermore, Aramwit et al. (2009) reported that with its high methionine content, sericin can promote the fastest growth rate of fibroblast cells. Methionine increases the accumulation of extracellular matrix components such as collagen type I and activates matrix metalloproteinases-9 as an active part in extracellular matrix modelling. Kato et al. (1998) demonstrated the antioxidant action of sericin by showing it suppresses in vitro lipid peroxidation and inhibits tyrosinase activity in rat brains. Previous studies by Chlapanidas et al. (2013) on in vitro stimulated peripheral blood mononuclear cells showed that sericin can serve as an ROS-scavenger. Following its addition to the culture medium for embryo production in vitro, sericin increased the percentage of maturation and in vitro fertilization of sheep oocytes in a medium without BSA (Yasmin et al., 2015), and increased the quality and pre-implantation development of bovine embryos that were cultured individually (Isobe et al., 2012). However, the role of sericin in DNA fragmentation or the concentration of $\mathrm{H}_{2} \mathrm{O}_{2}$ in oocytes matured in vitro has not been studied. Therefore, the objective of this study was to evaluate DNA fragmentation and the concentration of $\mathrm{H}_{2} \mathrm{O}_{2}$ of buffalo oocytes matured in maturation medium supplemented with sericin.

\section{Materials and Methods}

Buffalo ovaries were brought from the abattoir to the laboratory in $0.9 \% \mathrm{NaCl}$ supplemented with 100 $\mathrm{IU} / \mathrm{mL}$ penicillin and $100 \mu \mathrm{g} / \mathrm{mL}$ streptomycin sulphate. Each ovary was sliced with a scalpel blade to release the cumulus-oocyte complexes in phosphate buffered saline (PBS) supplemented with $0.3 \%$ bovine serum albumin (BSA) (Sigma-Aldrich) and antibiotics. Oocytes that were surrounded by compact cumulus layers and uniform ooplasm (cumulus-oocyte complexes) were used for this study. The basic maturation medium comprised tissue culture medium-199 (TCM-199) (Sigma, USA) supplemented with $10 \mathrm{IU} / \mathrm{mL}$ pregnant mare serum gonadotrophin (Intergonan) (Intervet Deutschland $\mathrm{GmbH}$ ), $10 \mathrm{IU} / \mathrm{mL}$ human chorionic gonadotrophin (Chorulo) (International Intervet BV Boxmeer-Holland), and $50 \mathrm{ug} / \mathrm{mL}$ gentamycin (Sigma, USA). Selected oocytes were washed three times and divided into groups, namely those matured in maturation medium without BSA (-BSA group), those matured with BSA only (+BSA group), and without BSA but with sericin (Wako Pure Chem. Industries, Ltd. Osaka, Japan) in varying concentrations $[0.025 \%(\mathrm{w} / \mathrm{v})(0.025$ Ser group), $0.05 \%$ (0.05 Ser group), $0.1 \%$ (0.1 Ser) or $0.25 \%$ (0.25 Ser)]. Oocytes were matured at a temperature of $38.5^{\circ} \mathrm{C}$ with $5 \% \mathrm{CO}_{2}$ for 24 hours.

After maturation, oocytes were denuded from the cumulus cells by repeated pipetting in PBS, which contained $0.25 \%$ hyaluronidase enzyme (Sigma, USA). After denudation, oocytes were fixed in methanol $(1: 3 \mathrm{v} / \mathrm{v})$, for 48 to 72 hours and then stained with aceto-orcein ( $2 \%$ orcein and $45 \%$ acetic acid). Nuclear maturation was observed under a phase-contrast microscope and classified based on the stage of maturation as germinal vesicle (GV), germinal vesicle breakdown (GVBD), metaphase I (MI), a-telophase I (ATI), metaphase II (MII) and degenerated.

The concentrations of $\mathrm{H}_{2} \mathrm{O}_{2}$ of matured oocytes were measured using DCHFDA (Sigma) as described by Karja et al. (2006) with minor modifications. Oocytes in each group were incubated for $15 \mathrm{~min}$ in maturation medium containing $10 \mu \mathrm{M}$ DCHFDA, and then washed in fresh medium before being placed on glass slides and covered with cover slips. Fluorescence emissions were recorded with a digital camera (Zeiss AxioCam HRc, Germany) attached to a fluorescence microscope (Zeiss Axio Imager A2) after excitation at $480 \mathrm{~nm}$ and $510 \mathrm{~nm}$ emission. The fluorescent image was converted to TIFF files using Adobe Photoshop CS3 (Adobe Systems Inc., San Jose, CA), then analysed with ImageJ software 1.47 (Sun Microsystems, Inc., California, USA). The fluorescent image was measured by counting the number of pixels after colour inversion. The fluorescence intensity represents the intracellular $\mathrm{H}_{2} \mathrm{O}_{2}$ concentration. 
Fragmentation of DNA and nuclear status of matured oocytes in each group were analysed using the combined technique for nuclear staining and TUNEL (in situ cell death detection system) (Roche Diagnostics Corporation, Indianapolis, IN, USA) (procedure modified after those described by Wongsrikeao et al. (2004)). Oocytes were fixed overnight at $4{ }^{\circ} \mathrm{C}$ in $3.7 \%$ (wt/vol) paraformaldehyde diluted in PBS. After overnight fixation, the oocytes were washed four times in PBS, which contained $3 \%(\mathrm{w} / \mathrm{v})$ polyvinyl alcohol (PVA) and permeabilized in $0.5 \%(\mathrm{v} / \mathrm{v})$ Triton-X100 for 1 hour, and then incubated in a blocking solution (PBS +10 $\mathrm{mg} / \mathrm{ml} \mathrm{BSA}$ ) overnight at $4{ }^{\circ} \mathrm{C}$. After being washed in PBS-PVA, positive controls and all treated oocytes were incubated in fluorescein conjugated dUTP and TdT (TUNEL reagent) at $38.5{ }^{\circ} \mathrm{C}$ for 1 hour in the dark. As positive controls, one to two oocytes per TUNEL analysis were incubated in $1000 \mathrm{IU} / \mathrm{mL}$ deoxyribonuclease I (DNase I) (Sigma) for $20 \mathrm{~min}$. Negative controls were incubated in fluorescein dUTP without TdT. After TUNEL, oocytes were washed three times in PBS-PVA, and later stained with $50 \mathrm{ug} / \mathrm{mL}$ propidium iodide (PI) for 20 min to label all nuclei. Oocytes were washed extensively in blocking solution and placed on a glass slide and covered with a glass cover. The oocytes were examined under a fluorescence microscope (Zeiss Axio Imager A2) using excitation at a wavelength of $488 \mathrm{~nm}$ and $568 \mathrm{~nm}$ to detect the reaction of TUNEL and $\mathrm{PI}$. The images were captured with a digital camera (Zeiss AxioCam HRc, Germany) (Figure 1). To assess the relationship between nuclear status and DNA fragmentation, chromatin staining of oocytes was used, classify them based on configuration from GV to MII. Those oocytes with diffusely stained cytoplasm characteristics of non-viable cells and those in which chromatin was not visible were excluded from DNA fragmentation analyses.

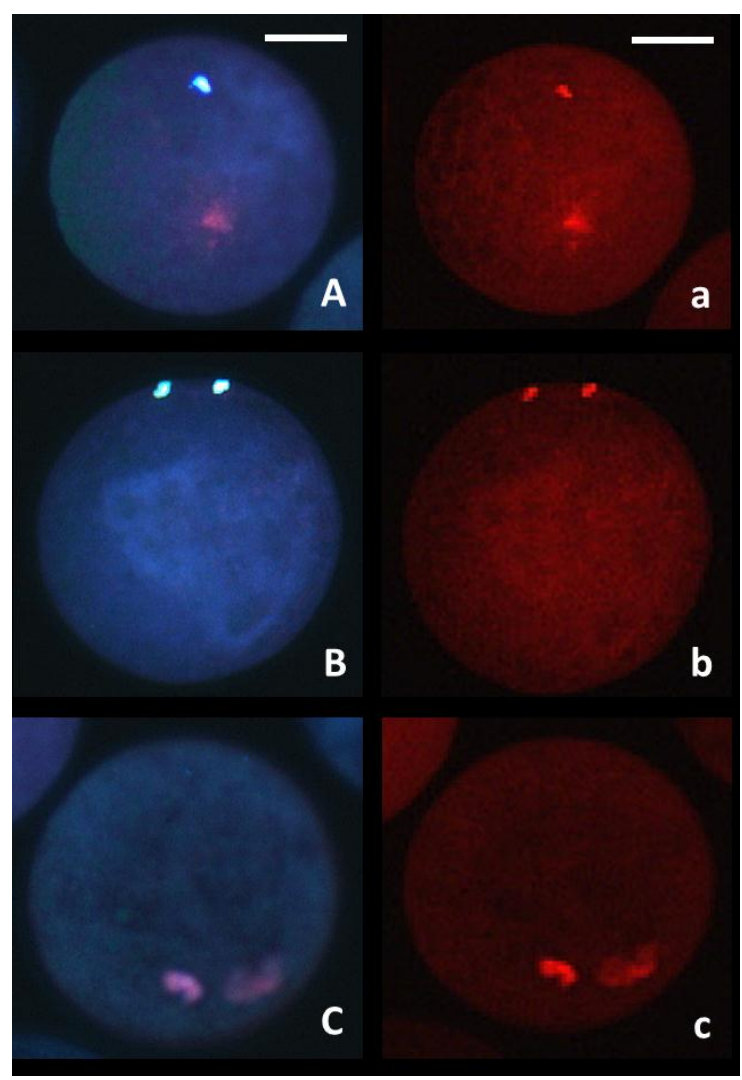

Figure 1 DNA fragmentation in buffalo oocytes stained by terminal deoxyribonucleotidyl transferasemediated dUTP-digoxigenin nick end-labelling (TUNEL) (left) and propidium iodide (PI) (right). MII-oocyte TUNEL-negative (red nucleus) with the polar body TUNEL-positive (A,a); MII-oocyte TUNEL-positive (bright nucleus) (B,b); and MII-oocyte TUNEL-negative (C,c)

Scale bars represent $40 \mu \mathrm{m}$

The results of the meiotic maturation rate, concentration of $\mathrm{H}_{2} \mathrm{O}_{2}$, and total proportion of TUNEL-positive oocytes are presented as the mean \pm SEM. Data were analysed by one-way analysis of variance (ANOVA). Statistical analysis was performed using SPSS for Windows version 21 . $P \leq 0.05$ was the criterion for statistical significance. 


\section{Results}

The highest proportion of oocytes reaching MII was found when oocytes were cultured in $0.05 \%$ sericin (89.2\%) $(P \leq 0.05)$ (Table 1). Although the MII rate of oocytes that were cultured in $0.025 \%$ sericin was significantly higher than that of oocytes cultured in (-BSA) $(P \leq 0.05)$, the rate was not significantly different from oocytes in the (+BSA) group. The proportion of oocytes reaching MII decreased when the concentration of sericin was increased $(P<0.05)(79.3 \%, 77.0 \%$, respectively, for 0.1 and $0.25 \%$ groups).

Table 1 Meiotic maturation of buffalo oocytes with supplementation of sericin in maturation medium

\begin{tabular}{|c|c|c|c|c|c|c|c|}
\hline $\begin{array}{l}\text { Groups } \\
\text { of IVM }\end{array}$ & $\begin{array}{c}\text { No. } \\
\text { oocytes } \\
\text { examined }\end{array}$ & $\begin{array}{l}\text { GV } \\
\text { (No) }\end{array}$ & $\begin{array}{l}\text { GVBD } \\
\text { (No) }\end{array}$ & $\begin{array}{c}\text { MI } \\
\text { (No) }\end{array}$ & $\begin{array}{l}\mathrm{Al} / \mathrm{TI} \\
\text { (No) }\end{array}$ & $\begin{array}{l}\text { MII } \\
\text { (No) }\end{array}$ & $\begin{array}{l}\text { Degenerated } \\
\text { (No) }\end{array}$ \\
\hline$(-B S A)$ & 89 & $2.4 \pm 1.8(2)$ & $12.8^{\mathrm{a}} \pm 5.0(10)$ & $10.2 \pm 3.1(10)$ & $0.0 \pm 0.0(0)$ & $71.9^{a} \pm 3.2(65)$ & $2.6 \pm 1.8(2)$ \\
\hline$(+B S A)$ & 85 & $1.1 \pm 1.1(1)$ & $3.1^{b} \pm 2.2(3)$ & $17.6 \pm 4.5(13)$ & $0.0 \pm 0.0(0)$ & $73.8^{\mathrm{ab}} \pm 3.0(64$ & $1.9 \pm 1.3(2)$ \\
\hline 0.025 Ser & 84 & $0.8 \pm 0.8(1)$ & $3.3^{b} \pm 1.6(3)$ & $8.3 \pm 2.9(6)$ & $2.8 \pm 1.4(3)$ & $83.0^{\mathrm{bc}} \pm 2.4(69)$ & $1.9 \pm 1.3(2)$ \\
\hline 0.05 Ser & 95 & $0.0 \pm 0.0(0)$ & $2.5^{\mathrm{b}} \pm 1.3(3)$ & $7.7 \pm 2.2(8)$ & $0.0 \pm 0.0(0)$ & $89.2^{\mathrm{c}} \pm 2.6(83)$ & $0.6 \pm 0.6(1)$ \\
\hline 0.1 Ser & 97 & $0.6 \pm 0.6(1)$ & $4.4^{\mathrm{ab}} \pm 2.5(5)$ & $10.8 \pm 4.3(11)$ & $1.0 \pm 1.0(1)$ & $79.3^{\mathrm{ab}} \pm 3.6(76)$ & $3.9 \pm 2.1(3)$ \\
\hline $0.25 \mathrm{Ser}$ & 87 & $1.0 \pm 1.0(1)$ & $7.7^{\mathrm{ab}} \pm 4.4(7)$ & $12.2 \pm 4.1(10)$ & $0.0 \pm 0.0(0)$ & $77.0^{\mathrm{ab}} \pm 4.3(67)$ & $2.1 \pm 1.5(2)$ \\
\hline
\end{tabular}

Results show the mean of percentage \pm SE

Means with different superscripts $\left({ }^{a, b, c}\right)$ in the same column differ significantly $(P \leq 0.05)$

Ser: sericin; BSA: bovine serum albumin; AI/TI: anaphase I and telophase I; GV: germinal vesicle; GVBD: germinal vesicle breakdown; MI: metaphase I; MII: metaphase II; No: number of oocytes

Fluorescent photomicrographs of buffalo oocytes stained with DCHFDA are shown in Figure 2. The concentration of intracellular $\mathrm{H}_{2} \mathrm{O}_{2}$ in oocytes is shown in Figure 3. The concentration of $\mathrm{H}_{2} \mathrm{O}_{2}$ in oocytes treated with $0.05 \%$ sericin (33.6 FIU/oocyte) was significantly lower $(P \leq 0.05)$ than in the (-BSA) group (39.9 FIU/oocyte), but not significantly different $(P>0.05)$ from other groups of $(+B S A)$, namely $0.025 \%, 0.1 \%$ and $0.25 \%$ (34.4\%, 34.7\%, 35.1\% and $37.9 \%$, respectively).

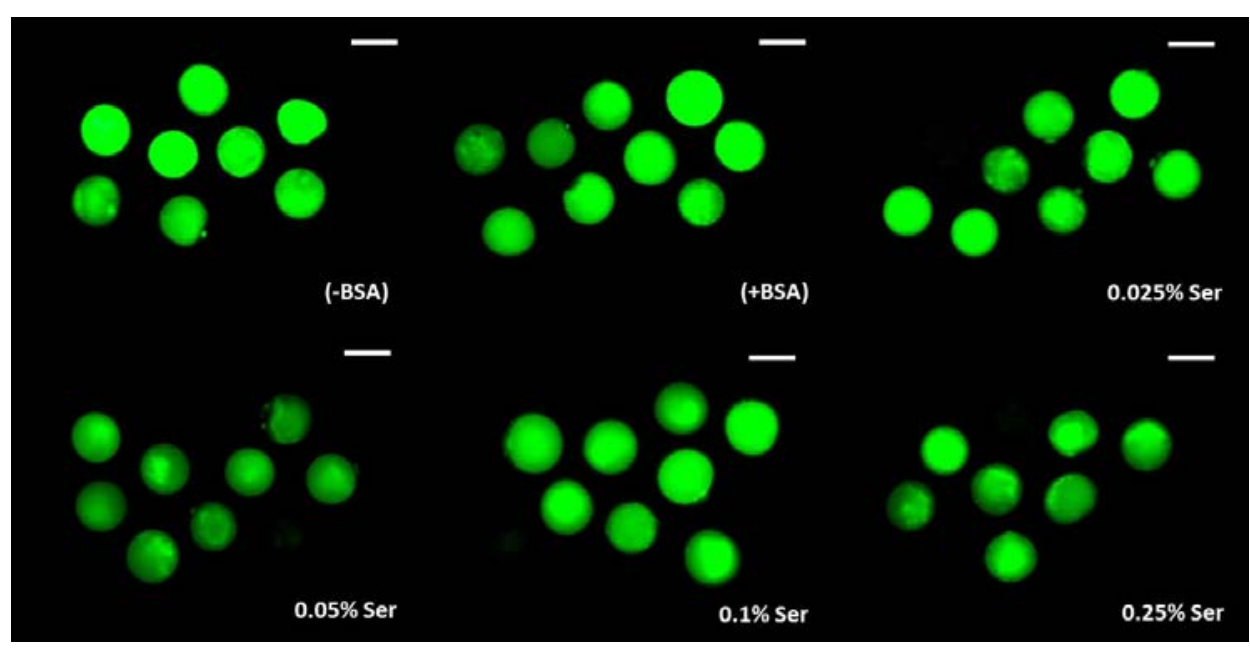

Figure 2 Fluorescent photomicrographs of buffalo oocytes stained with 2',7'-dichlorodihydrofluorescein diacetate sericin

Scale bars represent $140 \mu \mathrm{m}$ 


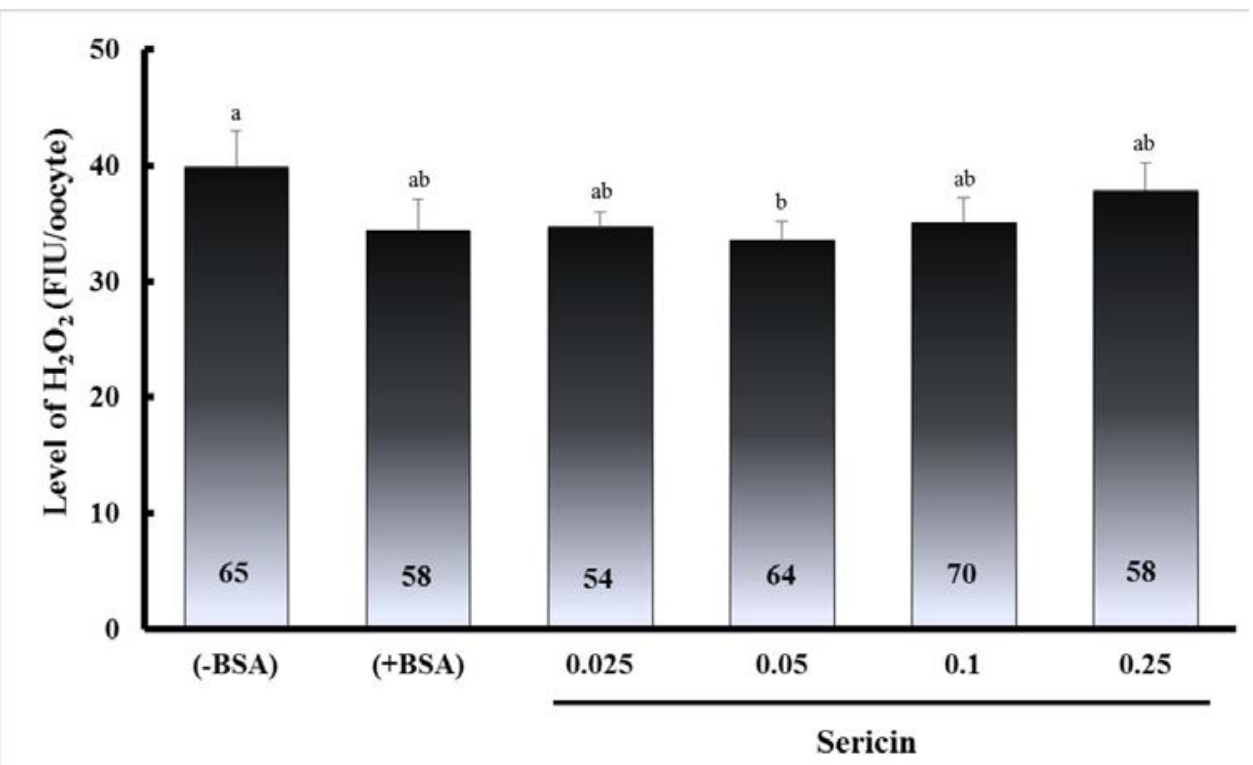

Figure 3 Hydrogen peroxide concentration in buffalo oocytes matured with and without sericin FIU: values represent fluorescence intensity units

Within each end point, bars with different letters $(a, b)$ are significantly different $(P \leq 0.05)$

The numbers on the bars represent the number of oocytes used for the assay

TUNEL results (Table 2) revealed no significant differences in the proportion of DNA fragmentation in oocytes at all of the nuclear stages after maturation among all groups $(P>0.05)$. However, the $0.05 \%$ sericin group has the lowest percentage mean of DNA fragmentation (7.1) in oocytes that remained at the MIl stage, whereas the (-BSA), (+BSA), 0.025, 0.1 and 0.25 groups had mean DNA fragmentation rates in oocytes that remained at MII of $15.8,9.4,9.1,9.2$ and 10.1 , respectively $(P>0.05)$.

Table 2 Nuclear DNA fragmentation of buffalo oocytes matured with sericin

\begin{tabular}{lcccccc}
\hline Groups of IVM & $\begin{array}{c}\text { No. oocytes } \\
\text { examined }\end{array}$ & GV & GVBD & MI & ATI & MII \\
\hline & 58 & $0.0 \pm 0.0(0 / 0)$ & $1.6 \pm 1.6(1 / 1)$ & $10.1 \pm 3.5(6 / 14)$ & $1.6 \pm 1.6(1 / 1)$ & $15.8 \pm 3.1(9 / 42)$ \\
$(-B S A)$ & 64 & $0.0 \pm 0.0(0 / 0)$ & $0.0 \pm 0.0(0 / 0)$ & $7.8 \pm 3.1(4 / 13)$ & $1.4 \pm 14(1 / 2)$ & $9.4 \pm 3.0(6 / 49)$ \\
$(+B S A)$ & 65 & $0.0 \pm 0.0(0 / 0)$ & $0.0 \pm 0.0(0 / 0)$ & $6.9 \pm 2.9(5 / 20)$ & $1.8 \pm 1.8(1 / 1)$ & $9.1 \pm 4.5(6 / 44)$ \\
0.025 Ser & 65 & $0.0 \pm 0.0(0 / 0)$ & $1.6 \pm 1.6(1 / 1)$ & $4.9 \pm 2.4(3 / 11)$ & $0.0 \pm 0.0(0 / 0)$ & $7.1 \pm 2.9(5 / 53)$ \\
0.05 Ser & 61 & $0.0 \pm 0.0(0 / 0)$ & $0.0 \pm 0.0(0 / 0)$ & $6.1 \pm 2.3(4 / 18)$ & $1.3 \pm 1.2(1 / 1)$ & $9.2 \pm 3.2(6 / 42)$ \\
0.1 Ser & 63 & $1.4 \pm 1.4(1 / 1)$ & $1.8 \pm 1.8(1 / 1)$ & $3.0 \pm 2.0(2 / 11)$ & $0.0 \pm 0.0(0 / 0)$ & $10.1 \pm 4.5(6 / 50)$ \\
0.25 Ser & & & & & & \\
\hline
\end{tabular}

Results show the mean of percentage \pm SEM, with the number of terminal deoxyribonucleotidyl transferase-mediated dUTP-digoxigenin nick end-labelling (TUNEL)-positive oocytes/total number of examined oocytes

$\mathrm{Al} / \mathrm{TI}$ : anaphase I and telophase I; GV: germinal vesicle; GVBD: germinal vesicle breakdown MI: metaphase I; MII: metaphase II

\section{Discussion}

During maturation and culturing, various factors can affect the quality and development of oocytes and embryos, especially environmental conditions. Oxygen tension during the culture process is influential on embryo development. Culture conditions under high oxygen tension have a negative effect that can induce the generation of ROS (Rocha-Frigoni et al., 2016). ROS can alter most types of cellular molecules, and block the development of pre-implantation embryos (Guerin et al., 2001). 
In this study, the addition of $0.05 \%$ sericin significantly increased the percentage of meiotic maturation of buffalo oocytes compared with the (-BSA) and (+BSA) groups. These data are consistent with the findings of Isobe et al. (2012) that the addition of $0.5 \%$ sericin can improve the quality and preimplantation development of bovine embryos. In sheep, maturation and fertilization rates can be improved with the addition of $0.1 \%$ sericin (Yasmin et al., 2015). On the other hand, the authors found that the level of nuclear maturation in the high concentration sericin group $(0.25 \%)$ showed a significant decrease, possibly owing to a toxic effect of sericin. According to Aramwit et al. (2010), sericin can increase collagen production, depending on the concentration, but high concentrations can cause cellular toxicity.

Furthermore, in this study, $0.05 \%$ sericin supplementation reduced the concentrations of intracellular $\mathrm{H}_{2} \mathrm{O}_{2}$ compared with the (-BSA) group. Dash et al. (2008) reported that sericin reduced levels of catalase, lactate dehydrogenase and the activity of malondialdehyde (markers of oxidative stress) in fibroblast cells exposed $\mathrm{H}_{2} \mathrm{O}_{2}$. Isobe et al. (2012) reported that sericin may have a unique antioxidant potential. The mechanism of the antioxidant effect of sericin is chelation of trace elements, because of its high content of hydroxyl amino acids (serine and threonine) (Kato et al., 1998).

Hydrogen peroxide penetrates biological membranes (Silva \& Coutinho, 2010). The mechanism of damage by $\mathrm{H}_{2} \mathrm{O}_{2}$ in cultured oocytes involves ROS derivatization. Reactive oxygen species can spread and pass through cell membranes and alter cellular molecules, such as proteins, lipids and nucleic acids, resulting in alterations in the mitochondria, embryo cell blockage, depletion of adenosine triphosphate (ATP) and DNA fragmentation (Guerin et al., 2001). DNA fragmentation indicates apoptosis, in which the generation of ROS can result in DNA strand breaks that arrest the cell cycle or even cause cell death (Fahrudin et al., 2002). Therefore, the authors also observed the index of DNA fragmentation in oocyte nuclei matured with sericin. Apoptosis is a normal process during preimplantation embryo development, which may be due to environmental stress and chromosome abnormalities (Matwee et al., 2000). Apoptosis is characterized by loss of phospholipid balance in the plasma membrane, chromatin condensation, DNA fragmentation and blebbing of the plasma membrane. In fragmentation, the cell becomes condensed and divides into several fragments, causing cytoplasmic condensation, condensed nuclei (Wyllie et al., 1980), and DNA breakdown, resulting in DNA fragments of 180 - 200 base pairs (Elmore, 2007).

This study demonstrated that although sericin can enhance the number of oocytes that reach MII, there were no significant differences in $\mathrm{H}_{2} \mathrm{O}_{2}$ concentration or the total of oocytes undergoing DNA fragmentation in all treatment groups. Although the reasons for this finding are currently unclear, the authors presume that it may be due to the effect of glutathione (GSH), which is a natural intracellular antioxidant. Levels of intracellular GSH increase during the oocyte maturation process in the ovary, and peak when oocytes reach MII (Deleuze \& Goudet, 2010). Similar to other species, buffalo oocytes can synthesize GSH de novo during IVM (Gasparrini et al., 2003). Nevertheless, the results of this study show that the addition of sericin to maturation media may serve as a replacement for BSA to increase the maturation rate, and reduce the concentration of $\mathrm{H}_{2} \mathrm{O}_{2}$ and the proportion of DNA fragmentation. Bovine serum albumin is the main soluble protein in the circulatory system and has many physiological functions. BSA serves as a depot protein and as a transport protein for a variety of compounds (Papadopoulou et al., 2005). It is generally used as a supplement in culture medium. Although BSA can protect cells and has many advantages, there are sanitary risks such as disease transmission, and it may serve as a contamination vector (Thibier, 2006). BSA is not only expensive in the long term, but it leads to enhanced risk of many zoonotic diseases (Cao \& Zhang, 2016). This finding is in agreement with other studies, which were reported by Yasmin et al. (2015) in sheep oocytes, and Terada et al. (2002) in several mammalian cell lines in which sericin was used to accelerate cell proliferation. Sericin may serve as an alternative supplement in serum-free media for cell culture (Tunma et al., 2013). Yanagihara et al. (2006) reported that sericin is a powerful alternative to the production of the adenoviral vector in human cells.

\section{Conclusion}

In conclusion, the current research findings suggest that supplementation of $0.05 \%$ sericin in the maturation medium enhances meiotic maturation of buffalo oocytes. Additionally, sericin can replace BSA as a supplement in serum-free medium, which at $0.05 \%$ may decrease the concentration of intracellular $\mathrm{H}_{2} \mathrm{O}_{2}$ in buffalo oocytes. Further research is warranted to evaluate the effects of sericin supplementation in the quality and development of buffalo embryos.

\section{Acknowledgments}

This work was supported by the Ministry of Research, Technology and Higher Education of the Republic of Indonesia (Grant No. 2604/E4.4/2012). 


\section{Author's Contributions}

SG contributed to the conception and design of the study, data collection, statistical analysis, interpretation of data and drafting the manuscript. HH contributed data collection, statistical analysis and interpretation of data. NWKK, MAS, and IS were involved in conception and design of study, and critical revision of manuscript.

\section{Conflict of Interest Declaration}

The authors certify that there is no conflict of interest with any financial organization regarding the material discussed in the manuscript.

\section{References}

Agarwal, A., Nallella, K.P., Allamaneni, S.S. \& Said, T.M., 2004. Role of antioxidants in treatment of male infertility: An overview of the literature. Reprod. Biomed. Online. 8, 616-627.

Altman, G.H., Diaz, F., Jakuba, C., Calabro, T., Horan, R.L., Chen, J., Lu, H., Richmond, J. \& Kaplan, D.L., 2003. Silkbased biomaterials. Biomaterials 24, 401-416.

Aramwit, P., Kanokpanont, S., De-Eknamkul, W., Kamei, K. \& Srichana, T., 2009. The effect of sericin with variable amino-acid content from different silk strains on the production of collagen and nitric oxide. J. Biomater. Sci. 20, 1295-1306.

Aramwit, P., Kanokpanont, S., Nakpheng, T. \& Srichana, T., 2010. The effect of sericin from various extraction methods on cell viability and collagen production. Int. J. Mol. Sci. 11, 2200-2211.

Cao, T-T. \& Zhang, Y-Q., 2016. Processing and characterization of silk sericin from Bombyx mori and its application in biomaterials and biomedicines. Mater. Sci. Eng. C. 61, 940-952.

Chauhan, M.S., Singla, S.K., Palta, P., Manik, R.S. \& Tomer, O.S., 1998. Develoment of in vitro produced buffalo (Bubalus bubalis) embryos in relation to time. Asian-Australas. J. Anim. Sci. 11, 398-403.

Chlapanidas, T., Farago, S., Lucconi, G., Perteghella, S., Galuzzi, M., Mantelli, M., Avanzini, M.A., Tosca, M.C., Marazzi. M., Vigo, D., Torre, M.L. \& Faustini, M., 2013. Sericins exhibit ROS-scavenging, anti-tyrosinase, anti-elastase, and in vitro immunomodulatory activities. Int. J. Biol. Macromol. 58, 47-56.

Dash, R., Acharya, C., Bindu, P.C. \& Kundu, S.C., 2008. Antioxidant potential of silk protein sericin against hydrogen peroxide-induced oxidative stress in skin fibroblasts. BMB Reports 41, 236-241.

Deleuze, S. \& Goudet, G., 2010. Cysteamine supplementation of in vitro maturation media: A review. Reprod. Domest. Anim. 45, e476-e482.

Drost, M., 2007. Advanced reproductive technology in the water buffalo. Theriogenol. 68, 450-453.

Elmore, S., 2007. Apoptosis: A review of programmed cell death. Toxicol. Pathol. 35, 495-516.

Engel, W., Hoppe, U., Pape, W. \& Sauermann, G., 1987. Eigenschaften eines sericinhaltigen, puffernden Shampoos. Arztl. Kosmetol. 17, 91-110.

Fahrudin, M., Otoi, T., Karja, N.W.K., Mori, M., Murakami, M. \& Suzuki, T., 2002. Analysis of DNA fragmentation in bovine somatic nuclear transfer embryos using TUNEL. Reproduction 124, 813-819.

Gasparrini, B., 2002. In vitro embryo production in buffalo species: State of the art. Theriogenol. 57, 237-256.

Gasparrini, B., Sayoud, H., Neglia, G., de Matos, D.G., Donnay, I. \& Zicarelli, L., 2003. Glutathione synthesis during in vitro maturation of buffalo (Bubalus bubalis) oocytes: effects of cysteamine on embryo development. Theriogenol. 60, 943-952.

Guerin, P., El Mouatassim, S. \& Menezo, Y., 2001. Oxidative stress and protection against reactive oxygen species in the pre-implantation embryo and its surroundings. Hum. Reprod. Update. 7, 175-189.

Hashimoto, S., Minami, N., Takakura, R., Yamada, M., Imai, H. \& Kashima, N., 2000. Low oxygen tension during in vitro maturation is beneficial for supporting the subsequent development of bovine cumulus-oocyte complexes. Mol. Reprod. Dev. 57, 353-360.

Isobe, T., Ikebata, Y., Onitsuka, T., Wittayarat, M., Sato, Y., Taniguchi, M. \& Otoi, T., 2012. Effect of sericin on preimplantation development of bovine embryos cultured individually. Theriogenol. 78, 747-752.

Johnson, M.H. \& Nasr-Esfahani, M.H., 1994. Radical solutions and cultural problems: could free oxygen radicals be responsible for the impaired development of preimplantation mammalian embryos in vitro? Bioessays 16, 31-38.

Karja, N.W.K., Wongsrikeao, P., Murakami, M., Agung, B., Fahrudin, M., Nagai, T. \& Otoi, T., 2004. Effects of oxygen tension on the development and quality of porcine in vitro fertilized embryos. Theriogenol. 62, 1585-1595.

Karja, N.W.K., Kikuchi, K., Fahrudin, M., Ozawa, M., Somfai, T., Ohnuma, K., Noguchi, J., Kaneko, H. \& Nagai, T., 2006. Development to the blastocyst stage, the oxidative state, and the quality of early developmental stage of porcine embryos cultured in alteration of glucose concentrations in vitro under different oxygen tensions. Reprod. Biol. Endocrinol. 4, 1-12.

Kato, N., Sato, S., Yamanaka, A., Yamada, H., Fuwa, N. \& Nomura, M., 1998. Silk protein, sericin, inhibits lipid peroxidation and tyrosinase activity. Biosci. Biotechnol. Biochem. 62, 145-147.

Kunz, RI., Brancalhão, R.M.C., Ribeiro, L.d.F.C. \& Natali, M.R.M., 2016. Silkworm sericin: Properties and biomedical applications. Biomed. Res. Int. 1-19.

Manjunatha, B., Gupta, P., Ravindra, J., Devaraj, M. \& Nandi, S., 2008. In vitro embryo development and blastocyst hatching rates following vitrification of river buffalo embryos produced from oocytes recovered from slaughterhouse ovaries or live animals by ovum pick-up. Anim. Reprod. Sci. 104, 419-426.

Matwee, C., Betts, D.H. \& King, W.A., 2000. Apoptosis in the early bovine embryo. Zygote 8, 57-68.

Morado, S.A., Cetica, P.D., Beconi, M.T. \& Dalvit, G.C., 2009. Reactive oxygen species in bovine oocyte maturation in vitro. Reprod. Fertil. Dev. 21, 608-614. 
Nandi, S., Raghu, H., Ravindranatha, B. \& Chauhan, M., 2002. Production of buffalo (Bubalus bubalis) embryos in vitro: Premises and promises. Reprod. Dom. Anim. 37, 65-74.

Neglia, G., Gasparrini, B., di Brienza, V.C., Di Palo, R., Campanile, G., Presicce, G.A. \& Zicarelli, L., 2003. Bovine and buffalo in vitro embryo production using oocytes derived from abattoir ovaries or collected by transvaginal follicle aspiration. Theriogenol. 59, 1123-1130.

Papadopoulou, A., Green, R.J. \& Frazier, R.A., 2005. Interaction of flavonoids with bovine serum albumin: A fluorescence quenching study. J. Agric. Food Chem. 53, 158-163.

Prasong, S., 2011. Screening of antioxidant activity of some Samia ricini (Eri) silks: Comparison with Bombyx mori. J. Biol. Sci. 11, 336-339.

Prommuak, C., De-Eknamkul, W. \& Shotipruk, A., 2008. Extraction of flavonoids and carotenoids from Thai silk waste and antioxidant activity of extracts. Sep. Purif. Technol. 62, 444-448.

Rocha-Frigoni, N.A.S,. Leão, B.C.S., Dall'Acqua, P.C. \& Mingoti, G.Z., 2016. Improving the cytoplasmic maturation of bovine oocytes matured in vitro with intracellular and/or extracellular antioxidants is not associated with increased rates of embryo development. Theriogenol. 86, 1897-1905.

Sarovart, S., Sudatis, B., Meesilpa, P., Grady, B.P. \& Magaraphan, R., 2003. The use of sericin as an antioxidant and antimicrobial for polluted air treatment. Rev. Adv. Mater. Sci. 5, 193-198.

Sato, W., Fukumoto, K., Yanagihara, K., Sasaki, M., Kunitomi, Y. \& Terada, S., 2011. Mitogenic effect of sericin on mammalian cells. BMC Proc: BioMed Central P121.

Silva, J.P., Coutinho, O.P., 2010. Free radicals in the regulation of damage and cell death - basic mechanisms and prevention. Drug Discov. Ther. 4, 144-167.

Takahashi, M., Tsujimoto, K., Yamada, H., Takagi, H. \& Nakamori, S., 2003. The silk protein, sericin, protects against cell death caused by acute serum deprivation in insect cell culture. Biotechnol. Lett. 25, 1805-1809.

Terada, S., Nishimura, T., Sasaki, M., Yamada, H. \& Miki, M., 2002. Sericin, a protein derived from silkworms, accelerates the proliferation of several mammalian cell lines including a hybridoma. Cytotechnology 40, 3-12.

Thibier, M., 2006. Biosecurity and the various types of embryos transferred. Reprod. Domest. Anim. 41, 260-267.

Tunma, S., Song, D-H., Kim, S-E., Kim, K-N., Han, J-G. \& Boonyawan, D., 2013. Immobilization of sericin molecules via amorphous carbon plasma modified-polystyrene dish for serum-free culture. Appl. Surf. Sci. 283, 930-940.

Wongsrikeao, P., Otoi, T., Murakami, M., Karja, N.W.K., Budiyanto, A., Murakami, M., Nii, M. \& Suzuki, T., 2004. Relationship between DNA fragmentation and nuclear status of in vitro-matured porcine oocytes: Role of cumulus cells. Reprod. Fertil. Dev. 16, 773-780.

Wyllie, A.H., Kerr, J.R. \& Currie, A., 1980. Cell death: the significance of apoptosis. Int. Rev. Cytol. 68, 251-306.

Yanagihara, K., Terada, S., Miki, M., Sasaki, M. \& Yamada, H., 2006. Effect of the silk protein sericin on the production of adenovirus-based gene-therapy vectors. Biotechnol. Appl. Biochem. 45, 59-64.

Yang, H.W., Hwang, K.J., Kwon, H.C., Kim, H.S., Choi, K.W. \& Oh, K.S., 1998. Detection of reactive oxygen species (ROS) and apoptosis in human fragmented embryos. Hum. Reprod. 13, 998-1002.

Yasmin, C., Otoi, T., Setiadi, M.A. \& Karja, N.W.K., 2015. Maturation and fertilisation of sheep oocytes cultured in serumfree medium containing silk protein sericin. Acta. Vet. Hung. 63, 110-117.

Zhang, Y-Q., 2002. Applications of natural silk protein sericin in biomaterials. Biotechnol. Adv. 20, 91-100. 